\title{
Desastres Socioambientais, Turismo e Resiliência: reflexões sobre o vazamento de óleo na costa do Nordeste do Brasil
}

\author{
Itamara Lúcia da Fonseca ${ }^{a}$ \\ Wagner Araújo Oliveirab
}

\section{Resumo}

0 artigo tem como objetivo apresentar uma reflexão acerca dos impactos causados pelo vazamento de óleo ocorrido na costa do Nordeste do Brasil no que tange ao campo do turismo, propondo estratégias de resiliência para destinos turísticos mediante desastres socioambientais. A pesquisa tem caráter exploratório e descritivo, com abordagem qualitativa. Foram realizadas as pesquisas bibliográficas e em sites institucionais estaduais e do Governo Federal, bem como em portais online de notícias. Os estados do Pernambuco, Ceará e Bahia foram selecionados para compor o recorte espacial por concentrarem o maior fluxo de turistas nacionais e internacionais no ano de 2019, de acordo com o Mapa do Turismo Brasileiro. 0 vazamento de petróleo afetou, até fevereiro de 2020, nove estados na região Nordeste. Diante da gravidade do desastre, governos estaduais, municipais e federal, com o auxílio de voluntários locais, realizaram ações para em prol do combate às manchas de óleo. Assim, foram indicados elementos associados à lógica do turismo que podem ser impactados diretamente pelos efeitos de desastres socioambientais, como: imagem, competitividade, planejamento e sustentabilidade e, por fim, são propostas estratégias, a partir da perspectiva da resiliência, para a gestão proativa de destinos turísticos que sofreram desastres socioambientais.

Palavras-chave: Turismo; Desastres socioambientais; Resiliência ambiental; Vazamento de óleo; Nordeste.

\begin{abstract}
Socio-environmental Disasters, Tourism and Resilience: reflections on the oil spill off the coast of Northeast Brazil

The article aims to present a reflection on the impacts caused by the oil spill that occurred on the coast of the Northeast of Brazil regarding the field of tourism, proposing resilience strategies for tourist destinations to deal with socioenvironmental disasters. The research is exploratory and descriptive with a qualitative approach. We searched bibliography, state and Federal Government institutional websites, and online news portals. The states of Pernambuco, Ceará, and Bahia were selected to compose the spatial clipping for concentrating the largest flow of national and international tourists in 2019, according to the Brazilian Tourism Map. The oil spill, up to February 2020, affected nine states in the Northeast region. Considering the severity of the disaster, state, municipal, and federal governments,
\end{abstract}

a. Doutoranda em Turismo pela Universidade Federal do Rio Grande do Norte, Natal, Rio Grande do Norte, Brasil. E-mail: itamaralf@hotmail.com

b. Doutorando em Turismo pela Universidade Federal do Rio Grande do Norte, Natal, Rio Grande do Norte, Brasil. E-mail: wagner.araujo.098@ufrn.edu.br 
with the help of local volunteers, carried out actions to combat oil stains. Thus, we indicated elements associated with the logic of tourism that can be directly impacted by the effects of socio-environmental disasters, such as: image, competitiveness, planning, and sustainability and, finally, proposed strategies, from the perspective of resilience, for proactive management of tourist destinations that have suffered socio-environmental disasters.

Keywords: Tourism; Socio-environmental disasters; Environmental resilience; Oil leak; Northeast.

\section{Resumem}

Desastres Socioambientales, Turismo y Resiliencia: reflexiones sobre el derrame de petróleo en la costa del Nordeste de Brasil

Este artículo tiene como objetivo reflexionar sobre los impactos provocados por el derrame de petróleo en la costa del Nordeste de Brasil en el ámbito del turismo, así como proponer estrategias de resiliencia para destinos turísticos ante desastres socioambientales. Esta es una investigación exploratoria y descriptiva, de enfoque cualitativo. Se realizaron búsquedas bibliográficas y en sitios web institucionales del gobierno estatal y federal, así como en periódicos en línea. Los estados brasileños de Pernambuco, Ceará y Bahía fueron seleccionados para componer el recorte espacial donde se había concentrado el mayor flujo de turistas nacionales e internacionales en 2019 según el Mapa Turístico de Brasil. El derrame de petróleo hasta febrero de 2020 afectó a 9 estados de la región. Ante la gravedad del desastre, los gobiernos estatal, municipal y federal, con la colaboración de voluntarios locales, llevaron a cabo acciones para combatir las manchas de aceite. Así, se señalaron elementos asociados a la lógica del turismo que pueden ser impactados directamente por los efectos de los desastres socioambientales, tales como: imagen, competitividad, planificación y sostenibilidad; finalmente, son propuestas estratégicas, desde la perspectiva de la resiliencia, para la gestión proactiva de destinos turísticos que han sufrido desastres socioambientales.

Palabras Clave: Turismo; Desastres socioambientales; Resiliencia ambiental; Derrame de aceite; Nordeste.

\section{INTRODUÇÃo}

0 mundo é preso em um ciclo de desastres - respostas - reparação - repetição, e os custos associados a esse padrão, estão subindo. Segundo o Relatório Anual do Escritório das Nações Unidas para Redução de Risco de Desastres 2019, o referido ano protagonizou em nível global, uma série de eventos notáveis de desastres que provocaram perdas econômicas estimadas em U $\$ 232$ bilhões de dólares e danos ambientais incalculáveis (Unisdr, 2019).

Dentre os fatores externos que influenciam e cercam o turismo, os desdobramentos causados por desastres socioambientais apresentam potencial para impactar diretamente destinos turísticos, empresas, comunidades e turistas, visto a condição de vulnerabilidade que recai sobre os espaços de reconhecida importância turística, como as praias, por exemplo.

Segundo as Unisdr (2017), a definição de desastres pode ser entendida como uma séria perturbação do funcionamento de uma comunidade ou sociedade, em qualquer escala, devido a eventos perigosos interagindo com condições de 
exposição, vulnerabilidade e capacidade, levando a uma ou mais perdas impactantes dos seguintes aspectos: humano, material, econômico e ambiental.

o Centro Nacional de Monitoramento de Alertas e Desastres Naturais do Brasil (CEMADEN), ao compartilhar da visão exposta pela UNISDR sobre os desastres socioambientais, afirma em seu Plano Diretor 2019-2022, que os desastres ocorrem na interface entre sociedade e meio ambiente, ocasionando impactos diretos e indiretos à população e o meio ambiente (Brasil, 2019).

Em agosto de 2019, o litoral do Nordeste do Brasil foi atingido por um dos maiores desastres socioambientais já registrados na história do país, provocado por vazamento de petróleo que se alastrou por mais de 70\% dos 3.300 quilômetros de litoral (Araújo, Ramalho \& Melo, 2020), ampliando como consequência, o rol complexo de desafios socioambientais que se acumulam e há tempos sinaliza a necessidade de alternativas que contribuam com mudanças efetivas no combate ou diminuição desses problemas.

Desse modo, o objetivo deste trabalho consiste em apresentar uma reflexão acerca dos impactos ${ }^{1}$ do vazamento de óleo na costa do Nordeste do Brasil para o turismo, e propor estratégias de resiliência para destinos turísticos frente à ocorrência de desastres socioambientais, a partir da análise conjuntural dos estados da Bahia, Pernambuco e Ceará. A escolha desses estados como fontes de pesquisa se constituiu por concentrarem o maior fluxo de demanda turística nacional e internacional no ano de 2019, de acordo com os dados do mapa de turismo brasileiro do Ministério do Turismo.

Assim, o trabalho encontra-se dividido em cinco seções além desta introdução. A segunda seção discute a inter-relação do turismo, desastres socioambientais e resiliência. A terceira seção apresenta os procedimentos metodológicos para a execução da pesquisa.

A quarta seção, é subdividida em cinco tópicos que apresentam a descrição do vazamento de óleo no Brasil, seguido do detalhamento do caso nos estados alvo da pesquisa, com ênfase nas ações de enfrentamento das manchas de óleo por parte dos estados e do Governo Federal, e, posteriormente, discutem-se as implicações do vazamento para o turismo sob a perspectiva da resiliência, sendo apresentado um quadro propositivo de ações para destinos turísticos mediante a ocorrência de desastres socioambientais. Por fim, são apresentadas as considerações finais elucidando algumas reflexões e lacunas de pesquisas possíveis de serem aprofundadas.

\section{DESASTRES SOCIOAMBIENTAIS, TURISMO E RESILIÊNCIA}

Ao passo em que a sociedade se transforma a relação dela com o meio ambiente se mostra continuamente contraditória (Balim, Mota \& Silva, 2014). Isso pode ser constatado além de estudos, pelos próprios descompassos da sociedade refletidos no meio ambiente ao longo dos anos.

1. A noção de impacto adotada neste trabalho se alinha à perspectiva socioambiental assumida por Vasconcelos e Coriolano (2008, p. 262) a partir do seguinte entendimento: "Impacto socioambiental é a reação na sociedade ou no meio ambiente a uma ação humana. Qualquer que seja a atividade humana trata-se de uma ação que causará uma ou diversas reações." 
No bojo dessa relação conflituosa, os países vêm presenciando a ocorrência, cada vez mais, frequente de diferentes tipos de desastres no meio ambiente, como incêndios, terremotos, deslizamentos de terra, tempestades, secas, temperaturas extremas etc. A formação desses cenários, não surpreendentemente, está associada diretamente ao modelo de desenvolvimento social pautado no consumo, no mau uso dos espaços e em iniciativas ineficientes de proteção à natureza, reforçando a condição de insustentabilidade do sistema econômico global que há muito já se autodenuncia. Esses impactos estão impondo a necessidade de posicionamentos globais integrados urgentes para a recuperação de um meio ambiente ecologicamente equilibrado.

De acordo com o Centre for Research on the Epidemiology of Disasters (CRED) criado pela Organização das Nações Unidas (ONU) e pelo governo Belga, as perdas econômicas globais por desastres chegaram aproximadamente a US $\$ 30$ bilhões de dólares em 2019. O CRED conceitua desastre como uma situação ou evento que sobrecarrega a capacidade local, necessitando de um pedido a nível nacional ou internacional, para assistência externa mediante evento repentino que causa grande dano, destruição e sofrimento humano (Cred, 2020). Sobretudo, é importante destacar que pelo caráter heterogêneo dos desastres podem envolver diferentes e numerosos elementos como baixa previsibilidade, rápida deflagração e perdas de vidas humanas.

Nessa perspectiva, o Ministério das Cidades (2018) considera que os desastres e a busca pela redução das ocorrências, pressupõem o conhecimento dos riscos, o aperfeiçoamento da governança, a destinação dos recursos adequados e a melhoria das ações de preparo para respostas eficazes, dentre outros, envolvendo iniciativas de reabilitação e reconstrução associadas à implementação de políticas públicas inovadoras e práticas.

Nesse sentido, a figura 1 apresenta o número de desastres por continente no ano de 2019, cujo ranking é formado pela Ásia, África, Américas, Europa e Oceania, sendo os 10 países mais afetados: Estados Unidos, Indonésia, China, Filipinas, Índia, Paquistão, Japão, França, Espanha e Brasil (Cred, 2020).

Figura 1 - Número de desastres por continente e ranking dos 10 países mais afetados em 2019

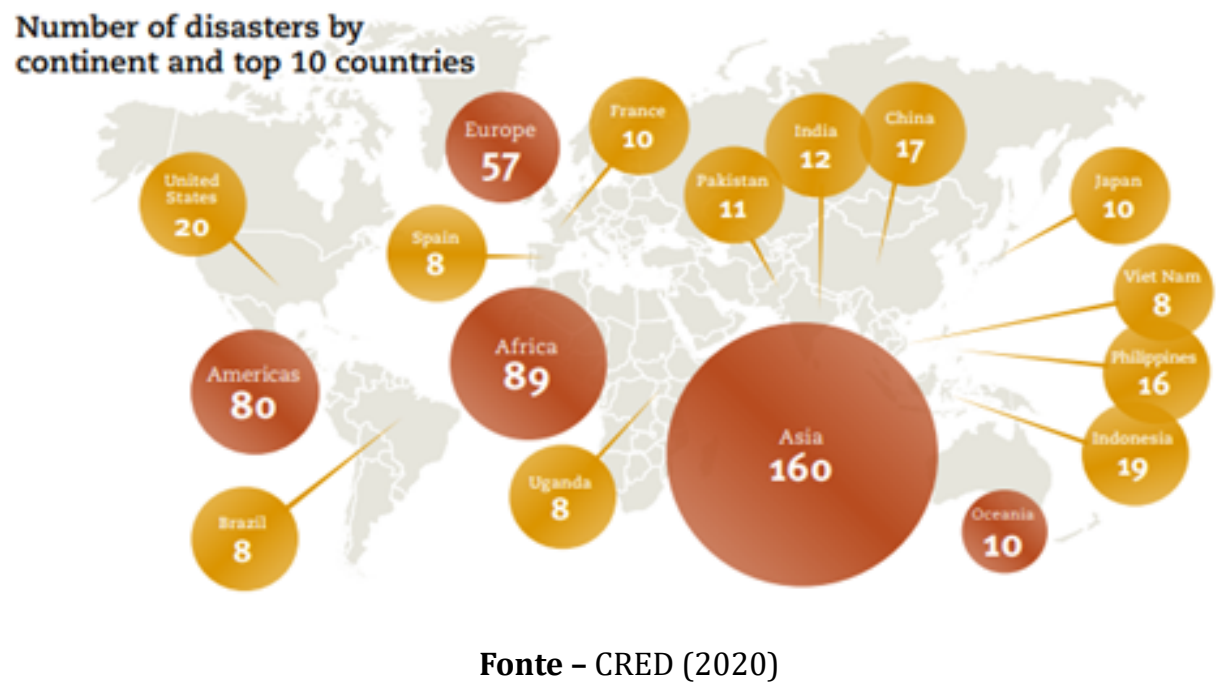


Dentre os desastres ocorridos no Brasil, destacaram-se o rompimento da barragem da Mina do Feijão em Brumadinho (MG), em 21 de janeiro de 2019, que provocou a degradação de 112 hectares de florestas nativas e vitimou cerca de 300 pessoas (Câmara Notícias, 2019); a detecção de 108 km² de desmatamento na Amazônia Legal (também no mês de janeiro) registrado pelo Sistema de Alerta de Desmatamento (SAD) (Imazon, 2019); e a ocorrência do vazamento de óleo na costa brasileira, que atingiu mais de $3 \mathrm{mil} \mathrm{km}$ de áreas no litoral.

Esses cenários, cada vez mais constantes, impõem que a sociedade busque repensar sobre novos posicionamentos e concepções quanto à proteção e conservação ambiental, uma vez que "a crise ambiental instituída é também uma crise da civilização e de percepção do homem diante do meio ambiente que lhe sustenta" (Balim, Mota \& Silva, 2014, p. 166).

Desse modo, no cerne dos desdobramentos causados, os destinos turísticos acabam imersos em uma camada ainda mais profunda de desafios por apresentarem características de extrema fragilidade, diante de alterações situacionais do meio em que o cerca, de maneira que, na iminência de desastres, todo o ecossistema da atividade é abalado e novas estratégias dentro dos campos da governança e planejamento turístico precisam a ser adotados.

Por momentos de vulnerabilidades, instabilidades e crises que se espalham a ponto de inviabilizar o sistema de turismo, é preciso atrelar a capacidade de adaptação/superação de crises à habilidade de inovação, e isto, está intimamente relacionado com a capacidade de planejar e gerir o turismo de modo sustentável e resiliente. Num contexto de crise, a resiliência emerge como uma opção para ações visando à antecipação e/ou previsão dessas ocasiões, como também uma possibilidade para reverter as consequências das crises (Costa \& Sonaglio, 2020).

A resiliência é um conceito debatido e aplicado em várias áreas do conhecimento, como na psicologia, na física, no âmbito empresarial e entre outros. No caso do turismo, é possível destacar, que pesquisadores vêm debruçando-se em novas abordagens para subsidiar os estudos numa tentativa de entender e compreender a dinamicidade do turismo. Desse modo, por sua vez, propor alternativas mais eficientes por meio da aplicação da resiliência, considerando o complexo cenário mundial contemporâneo que vem trazendo transformações com rapidez e mudanças repentinas (Sonaglio, 2018).

Entretanto, para enfrentar, resistir, adaptar-se e propor alternativas de combate às adversidades no turismo, é preciso resiliência atrelada a um processo de planejamento adequado e uma devida gestão eficiente. Dessa forma, resiliência no turismo é promover a capacidade de sistemas sociais, econômicos ou ecológicos de recuperar do estresse induzido pela própria atividade (Fabry \& Zeghni 2019; Sonaglio, 2018).

Nesse contexto, o gerenciamento da atividade turística deve aglutinar esforços constantes para uma gestão integradora e propositiva do desenvolvimento sustentável com alternativas econômicas e sociais (Faria \& Pires, 2007). Sendo assim, o desenvolvimento turístico deve buscar garantir, ao mesmo tempo, a conservação dos recursos naturais com sua prática e estabelecer diretrizes que sejam aplicáveis ao alcance de planos, projetos e ações visando auxiliar destinos turísticos sob a perspectiva resiliente e promover qualidade de vida às populações. 
Assim, a adoção da resiliência no contexto do turismo em destinos com forte presença da atividade, como por exemplo, as áreas litorâneas, pode subsidiar suporte na definição de medidas para reduzir suas vulnerabilidades, aumentar a preparação e as respostas dos locais frente às diferentes forças transformadoras de desastres socioambientais.

\section{METODOLOGIA DE PESQUISA}

O estudo em questão possui caráter exploratório e descritivo com abordagem qualitativa, cujos procedimentos metodológicos iniciais partiram da pesquisa bibliográfica, por meio da consulta de periódicos, teses e dissertações nacionais e internacionais disponíveis na internet e alinhadas à temática da pesquisa.

Como recorte espacial da pesquisa foram selecionados os estados de Pernambuco, Ceará e Bahia (Mapa 1), tendo em vista, primeiramente, a representatividade do turismo, enquanto atividade dominante economicamente e no que tange a atratividade dos elementos turísticos entorno do litoral desses estados.

Mapa 1 - Estados alvo da pesquisa

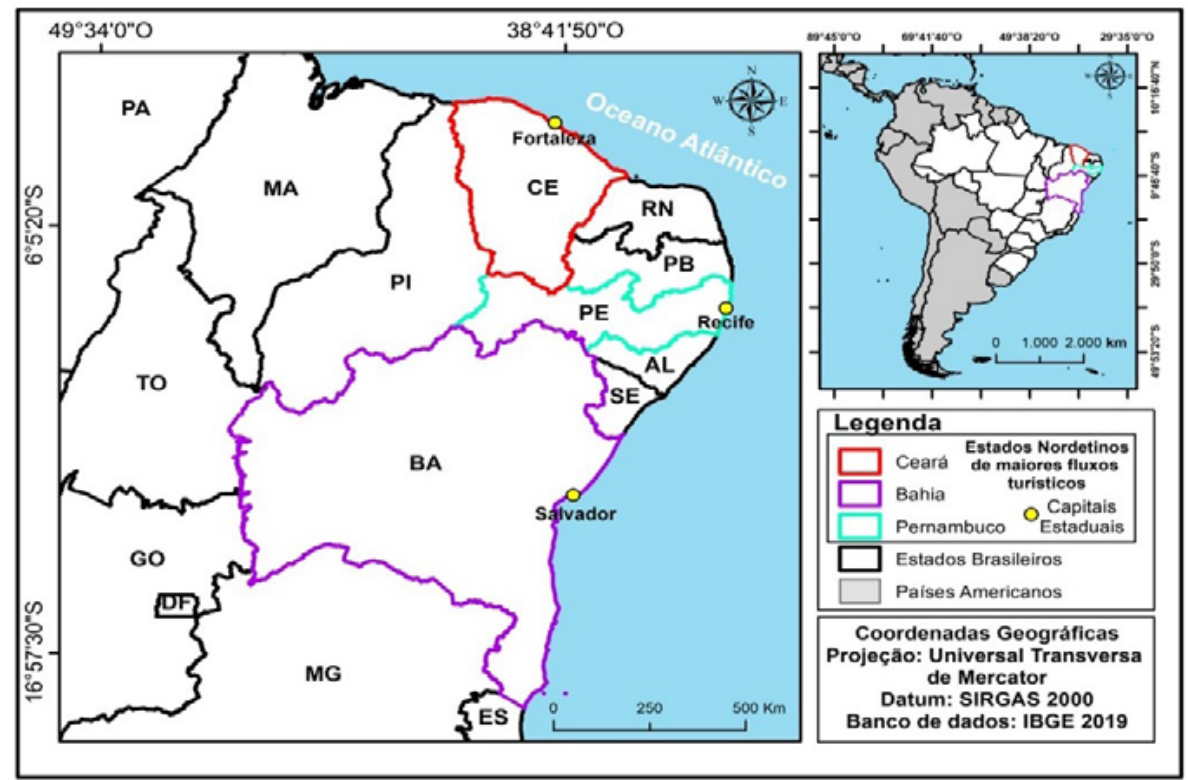

Fonte - Elaboração própria (2021)

Os três estados selecionados consistiram as regiões de maior concentração de fluxos de visitantes domésticos e internacionais no ano de 2019 , sendo considerado para essa definição, o somatório dos visitantes em ambos os níveis das regiões de categoria A, conforme classificação do Mapa do Turismo Brasileiro (Gráfico 1).

Para compor o corpus de análise foram realizadas duas etapas de pesquisa na internet, sendo a primeira constituída por consultas em sites institucionais das secretarias estaduais de meio ambiente e turismo, e em sites oficiais de órgãos públicos do Governo Federal, como o Instituto Brasileiro do Meio Ambiente e dos Recursos Naturais Renováveis (Ibama), Marinha do Brasil, Ministério do Turismo (Mtur), dentre outros, com a finalidade de identificar ações em prol do 
combate ao vazamento de óleo e iniciativas de fortalecimento para o turismo nos referidos estados alvo da pesquisa.

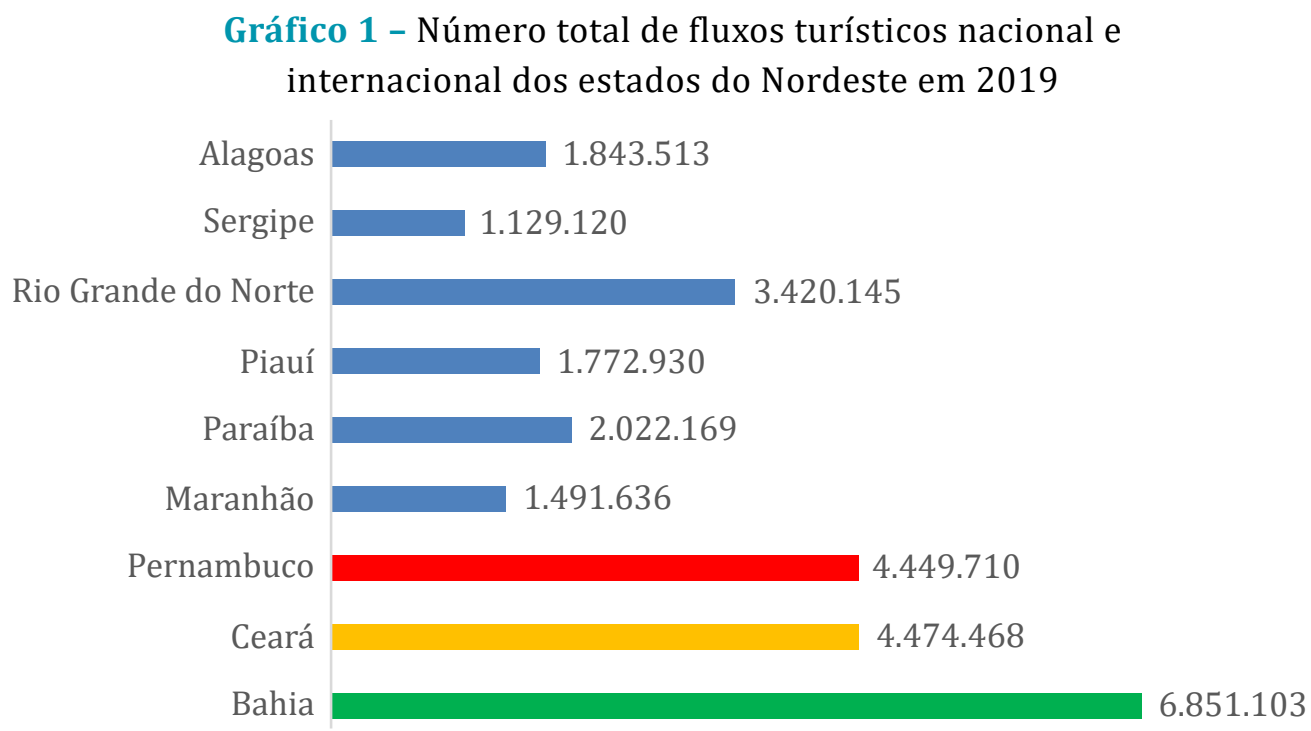

Fonte - Elaboração própria (2021) a partir do Mapa do Turismo Brasileiro (Mtur, 2020).

A segunda etapa se concentrou nas buscas de reportagens, sendo utilizado o portal de pesquisas Google, na aba notícias, as seguintes frases \palavras chaves, no campo de busca: "vazamento de óleo região nordeste 2019", "vazamento de óleo no Nordeste + Turismo". Para a seleção das notícias, foi dado prioridade para os portais de notícias de significativa veiculação nacional, internacional e estadual, como o Portal G1 (nacional e estadual), IstoÉ, Jornal El País, Correio Braziliense, dentre outros, sendo estes utilizados para interpretação e discussão dos resultados por meio da técnica descritiva de análise de dados.

\section{Resultados dA PESQUisa}

\section{Vazamento de óleo no litoral do Nordeste Brasileiro}

No Brasil a primeira mancha de óleo foi registrada no dia 30 de agosto 2019 no estado da Paraíba. Desde então, o vazamento alastrou-se por mais de $70 \%$ dos 3.300 quilômetros de litoral dos nove estados do Nordeste, atingindo quase 500 locais até o início de novembro (Araújo, Ramalho \& Melo, 2020).

O monitoramento do desastre contou com o trabalho do Ibama, como um dos principais órgãos atuantes diante da emergência ambiental ocorrida. De acordo com o Instituto, no período de 2 a 11 de setembro de 2019, foram atingidos pelo óleo os seguintes estados: Ceará, Rio Grande do Norte, Paraíba, Pernambuco e Alagoas. Segundo relatórios do Ibama, até fevereiro de 2020, 11 estados (9 no Nordeste e 2 na região Sudeste) e 130 municípios foram afetados, contabilizando assim, um total de 1009 localidades registradas em condições de contaminação de petróleo (Disner \& Torres, 2020).

Desde então, o Governo brasileiro tem investigado o caso na intenção de identificar os possíveis culpados pelos danos causados pelo óleo na costa do 
país (Brasil, 2019) sendo definidas estratégias de enfrentamento do desastre. Nesse sentido, apresenta-se a seguir as ações mais relevantes identificadas sintetizadas no quadro 1.

Quadro 1 - Ações de enfrentamento das manchas de óleo por parte do Governo Federal.

\begin{tabular}{|l|l|}
\hline Ações & Descrição \\
\hline Apoio Logístico & $\begin{array}{l}\text { Suporte logístico dado às ações do Grupo de Acompanhamento e } \\
\text { Avaliação (GAA), para atuação no processo de militares da Marinha Brasil, } \\
\text { a partir de navios, aeronaves, viaturas e servidores do IBAMA, ICMbio, } \\
\text { Defesa Civil e Petrobras }\end{array}$ \\
\hline $\begin{array}{l}\text { Limpezas das } \\
\text { praias }\end{array}$ & $\begin{array}{l}\text { Ações conjuntas com os governos estaduais e municipais e } \\
\text { voluntários de ONGs. }\end{array}$ \\
\hline Seguro Defeso & $\begin{array}{l}\text { Concessão de benefícios do seguro defeso a pescadores das áreas } \\
\text { afetadas, tendo sido destinado cerca de R\$ 59 milhões para atender } \\
\text { aproximadamente 360 mil pescadores. }\end{array}$ \\
\hline $\begin{array}{l}\text { Linha de Crédito } \\
\text { para o turismo }\end{array}$ & $\begin{array}{l}\text { Liberação de aproximadamente R\$ 200 milhões em linhas de crédito do } \\
\text { Fundo Geral do Turismo (FUNGETUR) pelo Ministério do Turismo. }\end{array}$ \\
\hline
\end{tabular}

Fonte - Brasil (2019).

0 Governo Federal aliou às ações a importância e necessidade de proteção e recuperação do ambiente natural, neste caso, o bioma marinho, de modo que foram realizadas ações do GAA em conjunto com as ações dos governos estaduais, municipais e voluntários de organizações não governamentais, tendo como foco a recuperação e limpeza dos lugares afetados, bem como, visando minimizar efeitos econômicos e ambientais às comunidades, sobretudo de pescadores, que tinham a pesca como principal fonte de subsistência familiar.

No tocante ao FUNGETUR, que consiste em um mecanismo de oferta de crédito a empresas ligadas direta ou indiretamente ao turismo, operado pelo Governo Federal (Mtur, 2018), facilitou a retomada da atividade turística em função do acesso a créditos e financiamentos por parte de empresários, contribuindo para impulsionar os negócios e minimizar os impactos negativos. Desse modo, face ao cenário de atuação federal, serão apresentados a seguir o contexto do vazamento e as principais ações no âmbito dos estados do PE, BA e CE.

\section{Descrição dos casos nos estados de Pernambuco, Ceará e Bahia}

Os primeiros casos de manchas de óleo no estado de Pernambuco foram registrados no dia 2 de setembro de 2019, nas cidades de Ipojuca no litoral Sul e Olinda (Meireles, 2019).

Logo após, as manchas foram registradas em Recife e em cidades da região metropolitana, como Tamandaré e Jaboatão dos Guararapes. Com um litoral de aproximadamente $187 \mathrm{~km}$ de extensão, as manchas foram espalhando-se ao longo da costa do PE contaminando 21 áreas com vestígios de óleo, a exemplo das praias de Porto de Galinhas e dos Carneiros consideradas como alguns dos principais atrativos turísticos do estado (Nascimento, 2020). 
Diante da gravidade do vazamento, o governo estadual do PE lançou edital de $\mathrm{R} \$ 2,5$ milhões para 12 projetos de pesquisa em parceria com instituições de ensino, como a Universidade Federal do Pernambuco (Meireles, 2019), para investigar e buscar soluções mitigadoras. Além dessa iniciativa, a Prefeitura Municipal do Recife mobilizou equipes de profissionais da Autarquia de Limpeza e Manutenção Urbana (Emlurb) e da Defesa Civil para atuarem na limpeza das praias da cidade, mediante o alerta de avanço das manchas e, consequentemente, da possível chegada do óleo no litoral da capital.

Conforme reportagem de Alves (2019), no portal G1 PE, o secretário de Turismo, Esportes e Lazer de Pernambuco, Rodrigo Novaes, relatou preocupação com a amplitude do caso nos meios de comunicação em todo o país, visto que poderia resultar em uma imagem negativa para o estado. Como medida para evitar essa questão, o secretário declarou a intenção de fortalecer a divulgação das demais praias do estado que não foram atingidas pelas manchas de óleo, como forma de manter a movimentação turística nesses locais.

No caso da ilha de Fernando de Noronha, apesar de não haver registro de manchas de óleo, representantes do Instituto Chico Mendes da Biodiversidade (ICMBio) com demais parcerias públicas e privadas locais, debateram estratégias de atuação frente a possível chegada do óleo no arquipélago, a partir, principalmente, de barreiras de contenção. As medidas tiveram um investimento orçado em torno de R\$290 mil (Marinho, 2019).

Em se tratando do estado do Ceará, cujo litoral possui extensão territorial de $573 \mathrm{~km}$, as primeiras manchas de óleo foram registradas no dia 7 de setembro de 2019, atingindo inicialmente as localidades de Morro Branco e Barra de Sucatinga, em Beberibe, e a Praia da Prainha, no município de Aquiraz (G1 CE, 2019).

A Secretaria Estadual de Meio Ambiente do Ceará com base nos dados fornecidos pelo Ibama, notificou até o dia 10 de novembro de 2019, 25 praias afetadas pelo óleo em 14 municípios, sendo estes: Aracati, São Gonçalo do Amarante, Caucaia, Icapuí, Paracuru, Barroquinha, Fortaleza; Aquiraz; Fortim, Jijoca de Jericoacoara, Cascavel, Paraipaba e Trairi, além de 28 registros de colônias de pescadores atingidas (Sema CE, 2019). Conforme notícia veiculada pelo G1 Natureza (2019), a última data de avistamento de manchas de óleo no estado foi 17 de janeiro de 2020, na Praia dos Caetanos, no município de Amontada (Bruno, 2019).

Diante da gravidade do desastre, o estado do Ceará anunciou a formação de um grupo de trabalho denominado de "Combate às Manchas de Óleo" para traçar estratégias de monitoramento e limpeza das praias, a fim de minimizar os impactos das manchas no litoral cearense. As ações derivadas dessa mobilização se destinaram a limpeza das áreas atingidas, atendimento aos animais oleados, vistoria e acompanhamento da situação das recentes manchas. Outras duas ações foram à verificação da extensão das manchas por meio de sobrevoos nas praias, operados por técnicos da Marinha e equipes de profissionais dos municípios afetados, além disso, a montagem de barreiras de contenção para reter fragmentos de petróleo cru transportados pelas águas (Bruno, 2019).

Em nota, no dia 3 dezembro de 2019, na página da Secretaria de Meio Ambiente do Estado, o secretário da pasta, Arthur Bruno, publicou informação sobre a redução da frequência das reuniões do GT em função do não surgimento de óleo visível na grande maioria das áreas de praia e manguezais. 
Além disso, notícias veiculadas no site G1 CE (2019) expressaram os possíveis impactos econômicos decorrentes desse contexto, citando que as autoridades representativas do setor no estado temiam os efeitos das manchas nos negócios turísticos em praias, como Barreiras, no município de Icapuí, visto que isso prejudicaria o fluxo de visitação. 0 portal ainda noticiou em 09 de outubro de 2019 , a redução de $40 \%$ do faturamento nas vendas de barracas na Praia do Futuro em Fortaleza, como também, queda nas vendas de restaurantes da região.

Por fim, no estado da Bahia, a chegada das manchas de óleo no litoral de $1.100 \mathrm{~km}$ de extensão ocorreu em 3 de outubro de 2019, quase um mês após o início do desastre ecológico no país (G1 BA, 2019). Locais de grande relevância turística no estado foram atingidos, como Morro de São Paulo (município de Cairu), as praias de Trancoso e Arraial d'Ajuda (Porto Seguro), e o arquipélago de Abrolhos, que concentra territorialmente o Parque Nacional Marinho de Abrolhos, uma das áreas com maior biodiversidade da América do Sul, além disso, é berço para baleias-jubarte e espécies raras de corais. No total, 31 cidades baianas foram atingidas, o que levou Governo do Estado a decretar situação de emergência (G1 BA, 2019).

Diante disso, uma das principais iniciativas articuladas consistiu na estruturação institucional do Comando Unificado de Incidentes, que compreendeu na formação de um grupo de representantes públicos de diferentes órgãos, como o IBAMA, a Superintendência de Proteção e Defesa Civil do Estado (Sudec), entre outros, com o objetivo de desenvolver as seguintes ações coordenadas em respostas ao avanço das manchas de óleo: a) limpeza das praias; b) fornecimento de equipamentos de proteção individual (EPIs), c) instalação de barreiras de proteção para contenção do óleo; d) apoio aos municípios com menor capacidade de investimento humano e material; e) estudo de identificação da origem e deslocamento das manchas; e f) viabilidade de destinação dos materiais coletados nas praias (Secretaria de Meio Ambiente da Bahia, 2019).

Em 12 de dezembro de 2019, o Comando Unificado de Incidentes encerrou seu caráter emergencial da articulação, passando as instituições envolvidas a serem subdivididas em grupos temáticos com foco nas ações de pesquisa, monitoramento e mitigação dos impactos socioambientais no estado (Secretaria de Meio Ambiente da Bahia, 2019).

Anterior a esse processo, a Secretaria de Cultura e Turismo de Salvador anunciou a promoção turística da capital ao Conselho Municipal de Turismo de Salvador, enfocando a partir de ações imediatas para o destino, como estratégia pós-manchas de óleo, estando dentre elas, a promoção do turismo de sol e praia. 0 evento aconteceu por meio de documentário com destaque para as ações da prefeitura e de moradores na retirada do óleo nas praias, divulgação das demais praias e atrativos não atingidos. Outra ação foi o programa "Vem pro centro", desenvolvida com foco em explorar turisticamente o centro histórico de Salvador (Agência de Notícias Salvador, 2019).

Assim, apoiando-se na representatividade desses casos e na relevância da temática junto ao turismo, apresenta-se a seguir, a discussão dos resultados da pesquisa sob as lentes da resiliência. 
Os desdobramentos dos impactos do vazamento de óleo na Costa do Nordeste Brasileiro e as proposições de ações e estratégias mediante a resiliência.

As questões ambientais têm transcendido sua própria lógica e já se expressam de forma indissociável dos demais campos e práticas sociais. Os destinos turísticos consolidados ou mesmo em processo de desenvolvimento, além de estarem submetidos a possíveis dependências econômicas materializadas pelas atividades características do turismo, estão imbuídos no contexto espacial e ambiental dos locais, levando a necessidade de dispor especial atenção para os diferentes fenômenos e impactos ocasionados no meio ambiente.

Mateos e Mendoza (2019, p. 236) afirmam que "os destinos turísticos estão cada vez mais sujeitos a choques externos e vulnerabilidades derivadas de desastres naturais de diversos tipos, que causam maiores impactos naqueles territórios de desenvolvimento turístico acelerado e desordenado, como ocorre em muitas áreas costeiras, montanhosas e florestais".

0 vazamento de óleo na costa brasileira, entendido aqui como um desastre provocado pela ação humana, foi uma verdadeira expressão de que planejamentos improvisados já não bastam como medidas de resolução para mitigar os impactos e efeitos no meio ambiente e nos demais fenômenos associados a ele, como o turismo.

Sobre isso, é importante ressaltar que no Brasil há um conjunto de mecanismos e aparatos técnico-científico-institucional, que garante a redução ou a minimização dos impactos nas zonas costeiras, que sofrem alguma incidência vinculada ao risco ou derramamento de óleo, sendo um dos exemplos, as Cartas de Sensibilidade Ambiental a Derramamentos de Óleo (Cartas SAO), que por sua vez, constituem ferramentas indispensáveis para o planejamento de contingência e a implementação de ações de resposta a incidentes de poluição por óleo. Portanto, é preciso então sair da inércia teórica e definir previamente diretrizes colaborativas entre os diferentes campos, uma vez que já não existem fronteiras.

Diante desse cenário, em relato, o Presidente da Associação Brasileira de Turismólogos e Profissionais do Turismo, Elzário Pereira indagou: “Como você vai atrair visitantes para uma região que está sendo afetada por uma substância química?" (IstoÉ, 2019). 0 enfoque dado pelo representante expressou a onda de preocupação inerente aos estados do Nordeste, cujos atrativos são os recursos naturais tidos como produtos turísticos. Especialmente nos estados da Bahia, Pernambuco e Ceará, enquanto macrorregiões turísticas de maior fluxo de visitação internacional e doméstica em 2019, a situação se mostrou ainda mais complexa em função do nível de dependência econômica atrelado ao turismo, que é retratado pelo quantitativo de empresas do setor, como se pode observar no gráfico a seguir.

No gráfico 2, são apresentadas algumas atividades características do turismo conforme a classificação nacional de atividades econômicas (CNAE), que revelam a concentração de 71 mil empregos no estado da Bahia ano de 2018, seguido por 34.677 empregos no estado do Ceará e 43.557 em Pernambuco, somando-se 149.235 empregos formais. Com destaque nos três estados encontravam-se os 
ramos de restaurantes e similares, organização de feiras, congressos e exposições e agências de viagens (DataSebrae, 2020).

Gráfico 2 - Número de Empresas do Setor de Turismo nos estados da PE, CE e BA - 2020

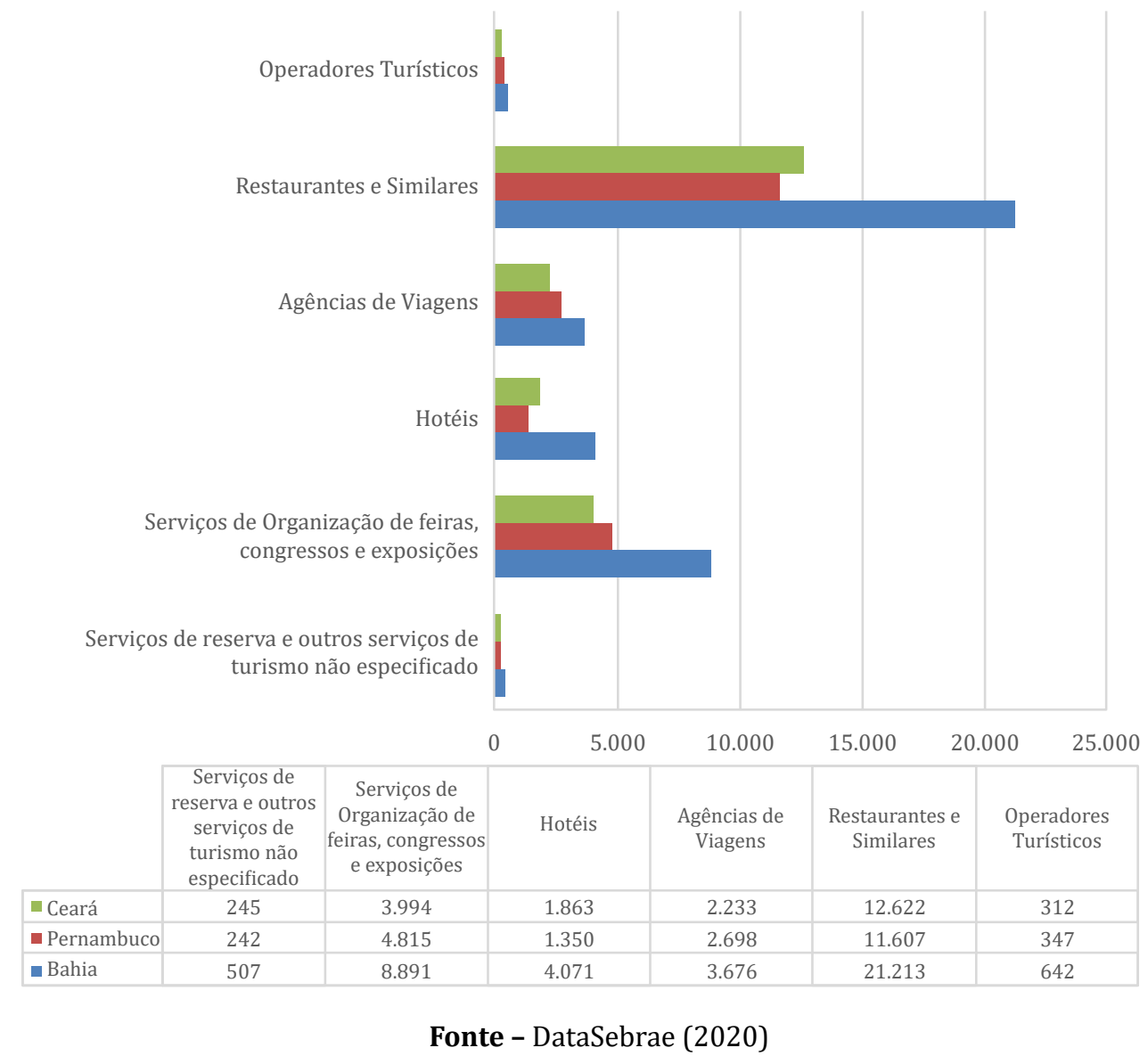

Tal expressividade denota uma relação de crescimento potencial de dependência econômica associada ao turismo no que tange a geração de empregos, criando rebatimentos na construção de um planejamento do setor, que possa englobar diferentes questões em torno da relação prática da economia gerada e os reflexos dos desastres socioambientais.

Uma vez envoltas no contexto das praias, como uns dos principais elementos na construção dos produtos turísticos desses estados, as empresas do setor ficaram sob a iminência de prejuízos (principalmente financeiros) diante da possibilidade de cancelamento de reservas e baixa procura por serviços, provocados pelos efeitos negativos na percepção de turistas, no que tange a imagem de destinos como Porto de Galinhas, Fortaleza e Salvador, por exemplos, atingidos pelas manchas de óleo.

No contexto de apontamento desses aspectos, o diretor da Associação Brasileira de Indústria de Hotéis (PE), Frederico Loyo, afirmou em depoimento noticiado pelo Portal G1 em 26 de outubro de 2019: "A gente tem percebido um volume menor de reservas, $3 \%$ a $4 \%$ de queda. Temos tido uma preocupação muito grande para mostrar ao turista e às pessoas que ainda estão comprando os seus pacotes de férias que há praias aptas a recebê-los" (Fonseca, 2019).

Somado a isso, o site G1 CE (2019) expressou em notícia os possíveis impactos econômicos decorrentes desse contexto no Ceará, evidenciando que as 
autoridades representativas do setor no estado temiam os efeitos das manchas de óleo nos negócios turísticos em praias como Barreiras, no município de Icapuí, em função da influência gerada na visitação turística pela situação dos locais atingidos. 0 portal ainda publicou em 09 de outubro de 2019 a notícia da redução de $40 \%$ do faturamento nas vendas de barracas na Praia do Futuro, em Fortaleza, assim como, queda nas vendas de restaurantes da região.

Já no cenário do estado da Bahia, o Jornal El País publicou em reportagem intitulada "Turismo sente reflexos do óleo no Nordeste, mas impacto é menor que o esperado" e o seguinte trecho: "a Secretaria de Turismo reconhece que houve uma "apreensão natural" com a chegada das manchas de óleo nas praias baianas, mas afirma que não houve impacto significativo no turismo" (Jucá \& Rossi, 2020).

No entanto, sabendo-se que "os danos ambientais e socioeconômicos provocados pelo vazamento de óleo no Nordeste foram incalculáveis" (Araújo, Ramalho \& Melo, 2020, p. 4), entende-se, mesmo diante de visões como do referido órgão público da Bahia, que a gravidade do desastre não permite tratamento ameno e percepções rasas, mas sim a compreensão de que novos cenários como esse poderão surgir. Isso reforça a necessidade de pôr ainda mais em pauta a discussão dessa abordagem e seus efeitos, de forma crítica e estratégica, visando uma articulação de ação estruturada e mais rápida.

Zucco e Magalhães (2011, p. 603) escrevem que "o turismo é altamente sensível a crises e elas se agravam quando associadas a desastres, de modo que um sistema de proteção aos turistas e de recuperação das áreas turísticas deve ser implementado pelas autoridades competentes." Esse contexto propicia enfocar que a permeabilidade dos destinos turísticos, no que tange a ocorrência de diferentes eventos, pode acabar gerando rebatimentos ambientais, estruturais, econômicos e políticos etc., nos espaços em que o turismo se desenvolve, criando assim maiores vulnerabilidades.

Desse modo, dentro da perspectiva dos desastres socioambientais, toda a oferta turística que é trabalhada para atrair e cativar turistas passa a ser ameaçada, tal como todos os aspectos de estruturação dos destinos, como complementa Rocha e Mattedi (2016, p. 2)

A partir do momento em que o setor turístico é afetado por alguns desastres, como uma catástrofe natural, acidente industrial, ataque terrorista, epidemia, entre outros, o cenário turístico até então perfeito e estruturado passará a demonstrar instabilidade em decorrência dos impactos gerados por esse fenômeno e, consequentemente, trazendo enormes prejuízos, principalmente os financeiros.

Nesse sentido, considerando as informações levantadas sobre a repercussão do caso do vazamento de óleo na costa do Brasil e refletindo-se sobre o efeito multiplicador de externalidades negativas que acometeram esses espaços (a exemplo das notícias apresentadas e dos impactos evidenciados na descrição dos casos), entende-se que a conjuntura dos desastres possui capacidade para gerar profundas implicações e crises para o turismo, como atividade envolta na dinâmica das áreas litorâneas. Nesse contexto, partindo-se das leituras dos autores Ahmed (1991), Tasci e Gartner (2007), Ritchie e Crouch (2010), Ruschmann (2001), Boff (2012) e Lage e Milone (1998), pôde-se eleger alguns elementos tanto potencialmente 
impactados na ocorrência de desastres, como também diretamente atingidos no cenário turístico dos estados em questão nesta pesquisa:

- Imagem do destino turístico;

- Competitividade de destinos turísticos;

- Planejamento Turístico;

- Sustentabilidade (dimensão social, cultural, política e econômica);

A seleção desses elementos se explica, dentre outros aspectos, por se constituírem como eixos centrais na organização da atividade turística, uma vez que é preciso considerar as diferentes dimensões que podem ser impactadas na dinâmica dos destinos turísticos.

Diante disso, tendo como base o contexto dos estados em evidência e a partir dos autores e elementos em destaque, entende-se que desastres como o vazamento de óleo tem alta capacidade para comprometer o turismo local/regional, a partir das seguintes implicações diretas: a) gerar impressões cognitivas negativas relacionadas aos destinos turísticos e desmotivar a realização de possíveis viagens; b) fragilizar a atratividade e a promoção dos destinos turísticos; c) forçar a reorganização ou criação imediata de ações emergenciais para minimizar os efeitos no turismo e em sua cadeia produtiva; d) impor a (re) estruturação de estratégias relativas à conservação dos recursos naturais, de suporte às comunidades locais e de organização socioespacial; e) reduzir o fluxo de visitação, gastos e receitas derivados dos turistas no consumo de serviços; f) reduzir investimentos nas empresas do setor; e g) afetar a disponibilidade e qualidade de serviços prestados pela cadeia produtiva do turismo.

Desse modo, as pressões derivadas dos desastres socioambientais forçam estados e empresas a adotarem posicionamentos estratégicos a fim de definir a curto, médio e longo prazos, novos caminhos de coexistência na relação homem-natureza, isto é, do uso e da conservação, embora as consequências possam se estender por meio do sentimento de insegurança e desconfiança no destino até que este não volte à sua normalidade (Muñiz \& La Torre, 2013).

Nesse sentido, apenas com um processo de planejamento estratégico adequado que inclua os elementos apresentados atrelados à governança do turismo, é que a recuperação e reconstrução das condições iniciais do destino podem ser garantidas ou melhoradas no âmbito da sua oferta turística e dos seus níveis de competitividade, ainda mais se pretende converter o setor do turismo em um catalisador para recuperação geral (Mateos \& Mendoza, 2019).

Nesse contínuo, considerando a complexidade territorial adquirida pelos destinos em função dos desastres socioambientais, enfatiza-se o modelo "Roda da Resiliência" (Figura 2) apresentado na publicação "Como Construir Cidades Mais Resilientes: Um Guia para Gestores Públicos Locais", que trata de 8 áreas funcionais, que devem ser priorizadas na dinâmica resiliente dos locais e que compõe a Campanha Global "Construindo Cidades Resilientes" da Organização das Nações Unidas (ONU). É importante ressaltar que a ONU trabalha com questões de governabilidade, a fim de ajudar governos locais a reduzir riscos e aumentar a resiliência em áreas urbanas através da aplicação do Marco de Sendai para a Redução do Risco de Desastres 2015-2030. 
Figura 2 - Roda da Resiliência

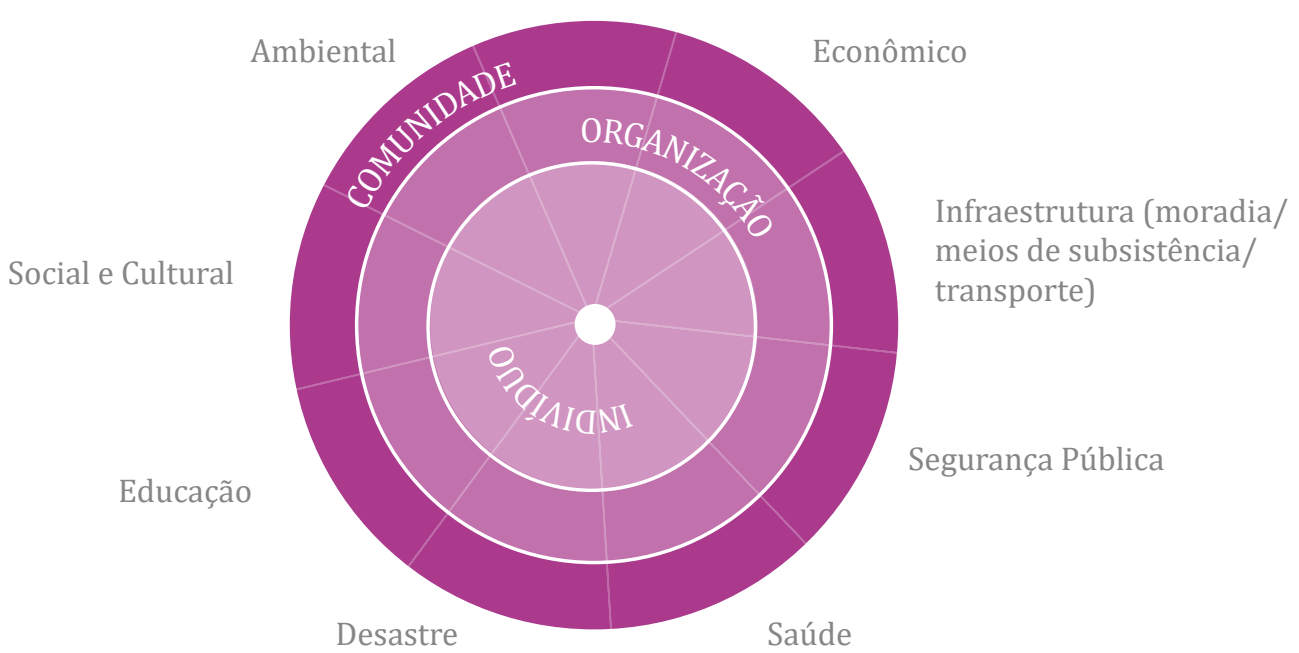

Fonte - UNISDR (2012)

A ênfase dada a esse modelo requer a capacidade de governamental e não governamental de estabelecer caminhos comuns em prol da sustentabilidade em suas dimensões tradicionais, ambiental, social e econômica, política e ética, fazendo jus a compreensão de um novo contexto global em que o trabalho setorializado não garante consistência em alcançar resultados práticos positivos diante de uma problemática que exige o esforço conjunto da sociedade.

Assim sendo, em resposta as implicações para o turismo apresentadas anteriormente, partidas caso do vazamento de óleo e atrelado aos elementos do modelo "Roda da Resiliência", apresenta-se a seguir algumas ações que podem ser adotadas para a gestão proativa de destinos turísticos, na intenção de contribuir para a construção de um marco referencial de orientações no que tange ocorrência de desastres socioambientais em áreas litorâneas.

Quadro 2 - Proposição de ações para destinos turísticos

frente a desastres socioambientais

\begin{tabular}{|l|l|l|l|}
\hline $\begin{array}{l}\text { Eixos da } \\
\text { Resiliência }\end{array}$ & $\begin{array}{l}\text { Foco } \\
\text { Estratégico }\end{array}$ & $\begin{array}{l}\text { Proposição de ações para destinos turísticos frente à } \\
\text { ocorrência de desastres socioambientais }\end{array}$ \\
\hline & $\begin{array}{l}\text { Criar sistemas de monitoramento e comunicação de } \\
\text { riscos potenciais de desastres entre governos federal, } \\
\text { estaduais e municipais; }\end{array}$ \\
\hline Institucional & $\begin{array}{l}\text { Eluação das } \\
\text { autoridade } \\
\text { lideranças } \\
\text { públicas e } \\
\text { articulação } \\
\text { intersetorial. }\end{array}$ & $\begin{array}{l}\text { templem dentre outros aspectos medidas estratégicas } \\
\text { de recuperação turística; }\end{array}$ \\
\hline & $\begin{array}{l}\text { Estabelecer acordos e compromissos de ativação de } \\
\text { protocolos de emergência nacionais e estaduais a fim } \\
\text { de alertar destinos frente a iminência de desastres; }\end{array}$ \\
\hline
\end{tabular}

(continua...) 
Quadro 2 - Continuação

\begin{tabular}{|c|c|c|}
\hline $\begin{array}{l}\text { Eixos da } \\
\text { Resiliência }\end{array}$ & $\begin{array}{l}\text { Foco } \\
\text { Estratégico }\end{array}$ & $\begin{array}{l}\text { Proposição de ações para destinos turísticos frente à } \\
\text { ocorrência de desastres socioambientais }\end{array}$ \\
\hline $\begin{array}{l}\text { Político- } \\
\text { Institucional }\end{array}$ & \begin{tabular}{l} 
Atuação das \\
autoridade\} $\\
{\text { lideranças }} \\
{\text { públicas e }} \\
{\text { articulação }} \\
{\text { intersetorial. }}$ & $\begin{array}{l}\text { - Planejamento colaborativo interinstitucional e parceria pú- } \\
\text { blico-privada para aplicação para a funcionalidade de políti- } \\
\text { cas públicas extensas a sustentabilidade urbana e ambiental. } \\
\text { - Orientação e fiscalização do uso responsável dos espaços tu- } \\
\text { rísticos direcionado aos turistas e populações locais. }\end{array}$ \\
\hline Ambiental & $\begin{array}{l}\text { Proteção, } \\
\text { conservação, } \\
\text { recuperação e o } \\
\text { uso sustentável } \\
\text { dos recursos } \\
\text { naturais }\end{array}$ & $\begin{array}{l}\text { - Mapear áreas de riscos potenciais em destinos turísticos; } \\
\text { - Alinhar/criar estratégias de conservação ambiental em áreas } \\
\text { de maior movimentação turística condizentes com os } 17 \text { ob- } \\
\text { jetivos de desenvolvimento sustentável (ODS); } \\
\text { - Ações contínuas de avaliação e monitoramento dos im- } \\
\text { pactos e implementação de medidas mitigadoras dos } \\
\text { efeitos nocivos no meio ambiente visando melhores con- } \\
\text { dições de sustentabilidade. }\end{array}$ \\
\hline Social & $\begin{array}{l}\text { Fortalecimento } \\
\text { das redes e } \\
\text { alianças sociais. }\end{array}$ & $\begin{array}{l}\text { - Disseminar informações para a sociedade sobre desastres e } \\
\text { seus impactos potenciais na vida humana e animal; } \\
\text { - Definir medidas assistenciais para populações potencial- } \\
\text { mente afetadas e acesso aos serviços públicos essenciais } \\
\text { para qualidade de vida e o bem estar; } \\
\text { - Incentivar o trabalho de organizações não governamentais } \\
\text { junto a comunidades locais no que tange ao uso e proteção } \\
\text { dos espaços e sua biodiversidade; } \\
\text { - Definir estratégias de segurança pública para populações } \\
\text { locais e turistas no entorno dos espaços com riscos poten- } \\
\text { ciais de desastre. }\end{array}$ \\
\hline Econômico & $\begin{array}{l}\text { Diversificação } \\
\text { das atividades } \\
\text { econômicas } \\
\text { e incentivos } \\
\text { financeiros }\end{array}$ & $\begin{array}{l}\text { - Estratégias de marketing turístico e de promoção de pro- } \\
\text { dutos e segmentos turísticos alternativos; } \\
\text { - Linhas de crédito para empresas do setor de turismo } \\
\text { com acesso facilitado aos recursos econômicos por par- } \\
\text { te dos mais vulneráveis; } \\
\text { - Atuação de grupos intersetoriais de trabalho para rede- } \\
\text { finir formas de promoção e maior competitividade dos } \\
\text { destinos turísticos afetados; } \\
\text { - Ampliação do investimento de capital em infraestrutura } \\
\text { básica e turística, incluindo reequipamento, renovação } \\
\text { e recuperação. }\end{array}$ \\
\hline
\end{tabular}
\end{tabular}

Fonte - Elaboração própria (2021) com base em UNISDR (2012)

Apesar da divisão por eixos como forma de organização das diferentes ações propostas, existe complementaridade entre todos os elementos apresentados, visto que não se enxerga potencial de efetividade em iniciativas unilaterais diante de riscos e danos potenciais em destinos turísticos.

Assim, em última análise, não sendo possível ignorar ou mesmo minimizar a vulnerabilidade socioterritorial que se amplia em esteira global, seria altamente contraditório manter posicionamentos meramente reativos, diante dos efeitos e danos trazidos pelo vazamento de óleo em macrorregiões turísticas significativas do Brasil, como $\mathrm{BA}$, PE e CE, dado as possibilidades de novos complicadores futuros. 
É preciso então, partir para a definição de modelos práticos que possam ser aplicados a casos locais e regionais de exposição a riscos potenciais, a fim de alinhar ações entre instituições públicas, populações e subsetores da atividade turística para refletir a necessidade de prevenção e de soluções no que concerne a desafios complexos que podem surgir principalmente pós-desastres.

\section{CONSIDERAÇÕES FINAIS}

Diante dos impactos ambientais causados pelo vazamento de óleo no litoral nordestino, ficou ainda mais notório o poder profundo de transformação que os desastres socioambientais podem acometer sobre destinos turísticos e alterar o funcionamento dos lugares. Isso se constitui como uma ameaça que interfere diretamente na confiança do turista e na segurança da comunidade, direcionando para a busca de novos caminhos que possam restabelecer a possível normalidade do turismo dentro de um contexto de crise que exige múltiplas e complexas de ações.

Frente a isso, os destinos turísticos litorâneos precisam despertar em suas definições de planejamento a atenção para a alta vulnerabilidade da atividade turística diante da iminência de desastres. Sobretudo, no que tange a dinamicidade socioambiental das localidades que pode ser afetada e, por consequência, os aspectos econômicos, assim, buscando precaver-se da melhor maneira possível de problemas futuros.

Constitui-se então, o entendimento de que os riscos de desastres socioambientais trazem consigo efeitos acumulativos para as localidades, principalmente, em áreas de alta relevância turística, como as regiões litorâneas. Esse pensamento se torna um importante passo para alinhar as premissas de atuação às definições dos Objetivos do Desenvolvimento Sustentável da ONU, como forma de contribuir para a sustentabilidade dos destinos turísticos, no que tange os elementos enfatizados dos eixos da resiliência, e principalmente, na promoção do bem-estar das populações locais e dos turistas.

Portanto, as ações propostas nesta pesquisa para a gestão proativa de destinos turísticos têm potencial prático para contribuir com a recuperação do turismo, a partir da perspectiva resiliente das localidades. Aplica-se este estudo aos cenários compartilhados pelos estados alvo da pesquisa, de modo a configurar caminhos possíveis de gestão e articulação entre os diferentes stakeholders da atividade turística, especialmente os órgãos públicos, na definição de respostas rápidas em situações semelhantes ao caso do vazamento de óleo na costa brasileira.

Por fim, dado o caráter reflexivo do estudo é preciso ressaltar que mesmo diante das reportagens e trechos de depoimentos trazidos para constituir o cerne da discussão, existiram limitações de pesquisa que muito mais se configuram como oportunidades para construção de novos trabalhos, retratados pela restrição dos dados e informações resgatadas da internet que não apresentam a dinâmica mais profunda e realística da totalidade dos impactos e efeitos do vazamento de óleo nos estados enfatizados.

Assim, as proposições de ações lançadas sob a ótica da resiliência devem ser consideradas conforme as particularidades de cada destino, não permitindo aplicações generalizadas e replicadas a outros contextos acometidos por desastres, 
de modo que novos debates e pesquisas futuras possam contribuir para novas reflexões no âmbito do turismo, desastres socioambientais e resiliência.

\section{REFERÊNCIAS}

Agências de Notícias Salvador. (2019). Secult apresenta ações de promoção de Salvador após a chegada de manchas de óleo. Salvador, Bahia, Recuperado em 13 de novembro, 2020, de http://www.agenciadenoticias.salvador.ba.gov.br/index.php/en/releases/cultura/12149secult-apresenta-acoes-de-promocao-de-salvador-apos-a-chegada-de-manchas-de-oleo.

Ahmed, Z. U. (1991). The influence of the components of a state's tourist image on product positioning strategy. Tourism Management. 12 (4), 331-340.

Alves, P. (2019). Turistas precisam saber que 'não é sempre que tem isso', diz secretário sobre manchas de óleo em praias do Nordeste. G1 PE, Pernambuco, 27 de setembro, Recuperado em 3 de agosto, 2020, de https://g1.globo.com/pe/pernambuco/ noticia/2019/09/27/turistas-precisam-saber-que nao-e-sempre-que-tem-isso-dizsecretario-sobre-manchas-de-oleo-em-praias-do-nordeste.ghtml.

Araújo, M. E; Ramalho, C. W. N.; Melo, P. W (2020). Pescadores artesanais, consumidores e meio ambiente: consequências imediatas do vazamento de petróleo no Estado de Pernambuco, Nordeste do Brasil. Caderno de Saúde Pública 36(1), 1-6. Recuperado em 9 de agosto, 2020, de https://www.scielo.br/pdf/csp/v36n1/pt_1678-4464csp-36-01-e00230319.

Balim, A. P. C; Mota, L. R; Silva, M. B. $O$ (2014). Complexidade ambiental: O repensar da relação Homem-natureza e seus desafios na sociedade contemporânea. Veredas do Direito. 11(21), 163-186. Recuperado em 9 de agosto, 2020, de https://heinonline. org/HOL/LandingPage?handle=hein.journals/rveredire11\&div=10\&id=\&page=.

Beni, M.C. (2020). Turismo e Covid-19: algumas reflexões. Rosa dos Ventos Turismo e Hospitalidade. 12 (3), 1-23. Recuperado em 21 de agosto, 2020, de http://www.ucs. $\mathrm{br} / \mathrm{etc} / \mathrm{revistas} /$ index.php/rosadosventos/article/view/8929.

Brasil (2019). Machas no litoral. Recuperado de 20 de agosto, 2020, de https://www. brasil.gov.br/manchanolitoral/.

Brasil. Ministério da Ciência, Tecnologia e Inovação. Centro de Nacional de Monitoramento e Alertas de Desastres Naturais (CEMADEN). Plano Diretor 2019-2022. Recuperado de 29 de março, 2021, de http://www.cemaden.gov.br/wp-content/uploads/2019/06/ Plano_Diretor_CEMADEN_2019-2022.pdf.

Boff, L (2012). Sustentabilidade: o que é - o que não é. Petrópolis: Vozes, BRASIL.

Bruno, A (2019). Prezados integrantes do Grupo de Trabalho de Combate às Manchas de Óleo no Litoral Cearense e representantes das administrações municipais. Secretaria do Meio Ambiente do Estado do Ceará, Ceará, Recuperado em 3 de agosto, 2020, de https://www.sema.ce.gov.br/2019/12/03/manchas-de-oleo-no-ceara.

Câmara notícias. (2019). Danos ambientais do desastre em Brumadinho são detalhados em comissão. Recuperado em 22 julho, 2020, de https://www.camara.leg.br/noticias/552767danos-ambientais-do-desastre-em-brumadinho-sao-detalhados-em-comissao/>.

Costa, S. P.; Sonaglio, K. E. (2020). Análisis del comportamiento resiliente de los gestores de turismo. Estudios y Perspectivas en Turismo - 30 Aniversario. 29 (20) 331-348, Recuperado em 25 de julho, 2020, de https://www.estudiosenturismo.com.ar/PDF/ V29/N02/v29n2a01.pdf.

Cred. (2019). Natural Disasters 2019 Brussels: CRED 2020. Recuperado em 28 de agosto, 2020, de https://www.emdat.be/publications. 
Datasebrae. (2020). DataSebrae indicadores. Recuperado 4 julho, 2020, de https:// datasebraeindicadores.sebrae.com.br/resources/sites/data-sebrae/data-sebrae. html\#> Acesso em 27 de agosto de 2020.

Disner, G. R.; Torres, M. (2020) The environmental impacts of 2019 oil spill on the Brazilian coast: Overview. Revista Brasileira de Gestão Ambiental e Sustentabilidade 7(15), 241255. Recuperado em 23 julho, 2020, de http://revista.ecogestaobrasil.net/v7n15/ v07n15a18.pdf.

Fabry, N, Zeghni, S (2019). Resilience, touristdestinationsandgovernance: ananalytical framework. Cholat F., Gwiazdzinski L., Tritz C., Tuppen J. Tourismes et adaptations, ElyaEditions, 96-108.

Faria, H. H. De; Pires, A. S (2007). Atualidades em Gestão de Unidades de Conservação. In Unidades de Conservação: Gestão e Conflitos. Org. Dora Orth e EmilianaDebetir. Editora Insular. Florianópolis, SC, 11-41.

Fonseca, D. (2019). Óleo em praias causa cancelamento de reservas em hotéis de PE, diz associação. G1 PE, Pernambuco, Recuperado 26 de julho, 2020, de https://g1.globo. $\mathrm{com} /$ pe/pernambuco/noticia/2019/10/26/oleo-em-praias-causa-cancelamento-dereservas-em-hoteis-de-pernambuco-diz-associacao-de-turismo.ghtml.

G1 BA (2019). Lista locais atingidos pelas manchas de óleo na Bahia. Bahia, 04 de nov. Recuperado em 3 de agosto, 2020, de https://g1.globo.com/ba/bahia/ noticia/2019/11/04/g1-lista-locais-atingidos-pelas-manchas-de-oleo-na-bahia.ghtml.

G1 CE (2019). Manchas de óleo já atingiram 21 praias do Ceará. Ceará, 24 de out Recuperado em 15 de agosto, de https://g1.globo.com/ce/ceara/noticia/2019/10/24/manchasde-oleo-ja-atingiram-21-praias-do-ceara.ghtml

G1 CE (2019). Manchas de óleo reduzem em 40\% faturamento do comércio da Praia do Futuro, em Fortaleza. Ceará, 24 de out. Recuperado de 13 de agosto de https://g1.globo. com/ce/ceara/noticia/2019/10/09/manchas-de-oleo-reduzem-em-40percentfaturamento-do-comercio-da-praia-do-futuro-em-fortaleza.ghtml.

G1 Natureza (2019). Lista de praias atingidas pelas manchas de óleo no litoral. São Paulo, 8 de out. Recuperado em 4 de agosto, 2020, de https://g1.globo.com/natureza/noticia/2019/10/08/ lista-de-praias-atingidas-pelas-manchas-de-oleo-no-nordeste.ghtml.

Jucá, B; Rossi, M (2020). Turismo sente reflexos do óleo no Nordeste, mas impacto é menor que o esperado. El País, 13 de jan. Recuperado em 22 de março, 2021, de https:// brasil.elpais.com/brasil/2020-01-13/turismo-sente-reflexos-do-oleo-no-nordestemas-impacto-e-menor-que-o-esperado.html.

Imazon. (2019). Boletim do desmatamento da Amazônia Legal janeiro 2019 SAD. Recuperado em 3 de agosto, 2020, de <https://imazon.org.br/publicacoes/boletimdo-desmatamento-da-amazonia-legal-janeiro-2019-sad.

Istoé. (2019). Turismo entra em alerta com vazamento de óleo em praias do Nordeste. 26 de set. Recuperado em 4 de agosto, 2020, de https://www.istoedinheiro.com.br/ turismo-entra-em-alerta-com-vazamento-de-oleo-em-praias-do-nordeste.

Marinho, A. C. (2019). Desastre provocado por manchas de óleo em praias do Nordeste é tema de encontro em Noronha. G1 PE, Pernambuco, 23 de out. Recuperado em 23 de julho, 2020, https://g1.globo.com/pe/pernambuco/blog/viver-noronha/ post/2019/10/23/desastre-provocado-por-manchas-de-oleo-em-praias-do-nordestee-tema-de-encontro-em-noronha.ghtml.

Mateos R. M.; Mendoza, F. A. G. (2019). Planificación estratégica y gobernanza en la recuperación de destinos turísticos afectados por desastres socio-naturales. Un estado de la cuestión. Investigaciones Geográficas, (72), 235-254. Recuperado em 3 de agosto, 2020, de http://rua.ua.es/dspace/handle/10045/99991. 
Meireles, M (2019). Com previsão de chegada de mais óleo ao litoral, PE anuncia edital de $R \$ 2,5$ milhões para analisar impactos. G1 PE, Pernambuco, 23 de out. Recuperado em 28 de julho, 2020, de https://g1.globo.com/pe/pernambuco/noticia/2019/10/23/ com-previsao-de-chegada-de-mais-oleo-ao-litoral-pe-anuncia-edital-de-r-25milhoes-para-estudar-prejuizos.ghtml>.

Meireles, M (2019). Manchas de óleo: três municípios pernambucanos retiram mais de 760 litros de resíduo de praias. G1 PE, Pernambuco, 09 de out. Recuperado em 28 de julho, 2020, https://g1.globo.com/pe/pernambuco/noticia/2019/10/09/manchasde-oleo-tres-municipios-pernambucanos-retiram-mais-de-760-litros-de-residuodas-praias.ghtml>.

Muñiz, D. R. T; La Torre, J. A (2013). Vulnerabilidad del turismo y comunicación institucional ante desastres. Redmarka: Revista académica de marketing aplicado, 2 (11), 137-161. Recuperado 2 de agosto, 2020, de https://dialnet.unirioja.es/ servlet/articulo?codigo $=4616885$.

Nascimento, A (2020). Pernambuco tem 21 áreas com vestígios de óleo nas praias. Diário Pernambuco \Correio Braziliense, Pernambuco, 03 jan. Recuperado em 28 de julho, 2020, de https://www.correiobraziliense.com.br/app/noticia/brasil/2020/01/03/ internabrasil,818084/pernambuco-tem-21-areas-com-vestigios-de-oleo-nas praias. shtml\#: :text=\%C3\%B3leo\%20que\%20atingiu $\% 20$ a $\% 20$ praia,sentir $\% 20$ o $\% 20$ odor\%20de\%20petr\%C3\%B3leo.

Ritchie, J. R. B., \& Crouch, G.I. (2010). A Model of Destination Competitiveness/ Sustainability: Brazilian perspectives. Revista de Administração Pública, 44(5), 1049-66.

Rocha, M. M.; Mattedi, A. M. (2016). A questão dos desastres em destinações turísticas: o caso da destinação Costa Verde e Mar em Santa Catarina. Turismo \& Sociedade, Curitiba, v. 9, n. 2, p. 1-23.

Ruschmann, D (2001). Turismo e Planejamento Sustentável. 8ª ed. São Paulo: Papirus.

Santos, D. (2019). O que se sabe até agora sobre o derramamento de óleo no Nordeste. WWF Brasil, 12 de nov. Recuperado em 28 de julho, 2020, de https://www.wwf.org. br/informacoes/noticias_meio_ambiente_e_natureza/?73944/0-que-se-sabe-ateagora-sobre-o-derramamento-de-oleo-no-Nordeste.

Secretaria de Meio Ambiente Bahia (2019). Manchas de óleo na Bahia: Comando Unificado de Incidentes é criado. Recuperado 1 de agosto, $2020 \mathrm{de} \mathrm{http://www.meioambiente.}$ ba.gov.br/2019/10/11870/Manchas-de-oleo-na-Bahia-Comando-Unificado-deIncidentes-e-criado.html.

Sema CE (2019). Manchas de óleo no Ceará - Informativos, 3 de dez. Recuperado em 24 de março, 2019, de https://www.sema.ce.gov.br/2019/12/03/manchas-de-oleo-no-ceara/.

Sonaglio, K. E (2018). Aproximações entre o turismo e a resiliência: um caminho para sustentabilidade. Revista Turismo - Visão e Ação - Eletrônica. 20(1), 80-104. Recuperado em 28 de agosto, 2020, de https://siaiap32.univali.br/seer/index. $\mathrm{php} / \mathrm{rtva} /$ article/view/12158.

Tasci, A. D. A.; Gartner, W. C (2007). Destination Image and its Functional Relationships. Journal of Travel Research. 45(4), 413-425.

United Nations International Strategy for Disaster Reduction - Unisdr (2019). Global Assessment Report on Disaster Risk Reduction. Geneva, Switzerland, United Nations Office for Disaster Risk Reduction (UNDRR). Recuperado em 8 de agosto, 2020, de https://www.undrrorg/.

United Nations International Strategy for Disaster Reduction - Unisdr (2015). Marco de Sendai para a Redução do Risco de Desastres 2015 - 2030. Recuperado em 8 de agosto, 
2020, de http://nacoesunidas.org/conferencia-de-sendai-adota-novo-marco-parareduzir-riscos-de-desastres-naturais-no-mundo.

Unisdr, United Nations International Strategy for Disaster Reduction. Terminology for Disaster Risk Reduction. Geneva, Switzerland, 2017. Recuperado em 20 de março, 2020, de https://www.preventionweb.net/terminology.

Unisdr, Nations International Strategy for Disaster Reduction - Unisdr. (2012). "Como construir cidades mais resilientes: um guia para gestores públicos locais". Genebra: Nações Unidas. Recuperado 10 julho, 2020 de http://www.unisdr.org/files/26462_ guiagestorespublicosweb.pdf.

Vasconcelos, F. P.; Coriolano, L. N. (2008). Impactos Sócio-Ambientais no Litoral: Um Foco no Turismo e na Gestão Integrada da Zona Costeira no Estado do Ceará/Brasil. Revista da Gestão Costeira Integrada, n.8, v.2, 259-275.

Zucco, F. D.; Magalhães, M. dos R. A. (2011). Gestão de Riscos e Desastres naturais no Turismo: um estudo do município de Blumenau/SC. Turismo em Análise, Balneário Camboriú, v. 21, n. 3, p. 594- 620.

Recebido em: 06/01/2021

Aprovado em: 14/04/2021

\section{CONTRIBUIÇÕES}

Itamara Lúcia da Fonseca: Definição do problema de pesquisa e objetivos; Desenvolvimento da proposição teórica; Realização da revisão bibliográfica e fundamentação teórica; Escolha dos procedimentos metodológicos; Coleta de dados; Análise de dados; Elaboração de tabelas, gráficos e figuras; Realização de cálculos e projeções; Revisão crítica do manuscrito; Redação do manuscrito.

Wagner Araújo Oliveira: Definição do problema de pesquisa e objetivos; Desenvolvimento da proposição teórica; Realização da revisão bibliográfica e fundamentação teórica; Escolha dos procedimentos metodológicos; Coleta de dados; Análise de dados; Elaboração de tabelas, gráficos e figuras; Realização de cálculos e projeções; Revisão crítica do manuscrito; Redação do manuscrito; Adequação do manuscrito às normas da RTA. 